\title{
On the incidence and prevalence of child maltreatment: a research agenda
}

\author{
Andreas Jud ${ }^{1,2^{*}}$, Jörg M. Fegert ${ }^{1}$ and David Finkelhor ${ }^{3}$
}

\begin{abstract}
Research on child maltreatment epidemiology has primarily been focused on population surveys with adult respondents. Far less attention has been paid to analyzing reported incidents of alleged child maltreatment and corresponding agency responses. This type of research is however indispensable to know how well a child protection system works and if the most vulnerable are identified and served. Notable findings of child maltreatment epidemiological research are summarized and directions for future studies discussed.
\end{abstract}

\section{Background}

Child maltreatment ${ }^{1}$ can have a devastating impact on children; adverse psychological, somatic and social consequences that affect childhood and later adult development and even persist into old age (e.g., [4-9]). ${ }^{2}$

There is widespread agreement that in order to make progress in the prevention and reduction of child maltreatment it is important for policy-makers to have information on its scope and characteristics ${ }^{3}$. Researchers around the world have typically responded to this need using surveys to count the prevalence of child maltreatment in the general population. Hundreds of such studies have been done in dozens of countries and subordinate jurisdictions. They often associate the prevalence of victimization in childhood with (long-term) health and social outcomes in the adult population.

However, general population surveys have limited implications for specific policies in child protection. What policy-makers need most is information about which officials or agencies in their jurisdictions have knowledge of the problem, and what they are doing or not doing when they encounter it. Based on this information they can make concrete plans about how to allocate resources, change practices, train officials, and reorganize systems to better respond. They need information on whether these cases are coming to the attention of school

\footnotetext{
*Correspondence: andreas.jud@hslu.ch

${ }^{2}$ School of Social Work, Lucerne University of Applied Sciences and Arts, Lucerne, Switzerland

Full list of author information is available at the end of the article
}

teachers or police or doctors and what these professionals are doing. It may turn out that some officials are encountering very few cases; perhaps they need more training. It may turn out that other officials are finding cases but failing to do anything about them. Or cases that would be best dealt with by doctors are instead primarily coming to the attention of teachers but not getting referred. This knowledge can promote strategies for change. As policy-makers make changes, provide training, and raise awareness, they will then want to know if their reforms are changing the patterns they originally observed.

The most useful studies for policy-makers are the ones with information about the agencies and officials who are in positions to help and respond. In comparison to population surveys, where children and families are surveyed directly, "agency surveys" collect data from community and government organizations involved with children, such as schools, law enforcement, hospitals, mental health agencies, family service agencies, NGOs, and child protection agencies. This commentary will address need for future research for the relative wealth of population

\footnotetext{
${ }^{1}$ We use the term child maltreatment to refer to both acts or series of acts of commission or omission by a parent or other caregiver that results in harm, potential for harm, or threat of harm to a child [3]. Subtypes included are child neglect and sexual, physical and psychological abuse.

2 This commentary is partly based on a report for the German Independent Commissioner for questions related to child sexual abuse [1]. Part of the development of the report was an international expert meeting in December 2014 in Berlin with the participation of David Finkelhor, Carl-Göran Svedin and Nico Trocmé [2].

${ }^{3}$ The following two paragraphs have been slightly adapted from Jud et al. [10].
} 
surveys and identify a framework for improving research on agency response to child maltreatment.

\section{Population surveys}

Since Finkelhors' review of international epidemiology on child sexual abuse in 1994 [11], prevalence studies on child sexual abuse have been meta-analyzed repeatedly [12-14]. Stoltenborgh et al. [14] included 331 independent samples in their meta-analysis with a total of around 10 million participants. While prevalence rates on child sexual victimization varied notably around $12.7 \%$ (95\% CI 10.7-15.0\%), a significantly higher rate of victimized females was widely but not universally observed. Findings on regional differences, socioeconomic development of a nation and on other indicators have been less clearcut $[12,14]$. A large part of the variation remains unexplained and differences are to some degree due to varying definitions and methodological artefacts. Small sample size, non-random design, low return rate and large number of items tend to increase the prevalence rate of a study $[12,14]$. At the least representative samples should be a sine qua non for prevalence surveys.

In a recent series, Stoltenborgh and colleagues [15-17], have also reviewed surveys on the prevalence of neglect, physical maltreatment and emotional abuse. Like the findings on child sexual abuse, the variation in prevalence rates for other forms of child maltreatment is vast, too; definitional disparities and methodological artifacts are important contributors to variation. However, no skewed gender distribution is reported outside of child sexual abuse. A 'neglect of neglect' (e.g., [18]) is still evident in research on child maltreatment with the review on neglect being able to summarize only 16 studies [16].

Beside definitional issues that affect all research on child maltreatment and will be addressed below, two recommendations are offered for the relatively well trodden path of population surveys. Most population surveys are directed towards adult survivors of child maltreatment through telephone interviews or self-administered questionnaires (Stoltenborgh et al. [14-17]). Not only are the adult participants' responses afflicted by memory biases, these retrospective studies also provide rates of maltreatment that apply to the past, often at least a decade ago. Self-reports of adolescents, on the other hand, provide a more current view on the scope of the problem and respondents' memory is less affected by a long delay. In combination with studies on agency response to child maltreatment, only surveys with adolescents' self-reports can provide accurate information on underserved populations. Furthermore, surveys with adolescents might provide a more accurate view on peer-to-peer violence (e.g., [19]). To address limitations of a particular source of information, researchers can also combine caregiver reports on child maltreatment with adolescents' selfreports [20, 21]. Overall, the benefits of adolescent self-reports outweigh the added costs of preparing and managing a survey with legally minor participants. As a second recommendation, more attention should be given to including and/or oversampling high-risk populations $[22,23]$.

\section{Agency surveys and administrative data}

While there is a solid body of research on measuring child maltreatment prevalence through self-report surveys, far less attention has been paid to studying incidents of child maltreatment known to agencies (cf. [24]). However, a few countries, such as the United States, New Zealand, and the Netherlands, have collected data on how their service agencies are responding to child maltreatment, mainly using two distinct data collection strategies: professional surveys and/or administrative data extraction (cf. [25]).

Globally, only three cross-sectional professional surveys are currently conducted on a cyclical basis on the nature and the extent of child maltreatment: the (U.S.) National Incidence Study of Child Abuse and Neglect (NIS) (e.g., [26, 27]), the Canadian Incidence Study of Reported Child Abuse and Neglect (CIS) (e.g., Public Health Agency of Canada [28, 29]), and the Netherlands nationwide prevalence study of child maltreatment (NPM) (e.g., [30]). All three surveys rely on data obtained from nationally representative samples of child protective services workers during a 3-month reference period. Representativeness is achieved through a universal inclusion strategy or stratified random sampling of child protective services. The incidents are extrapolated to an estimate of the annual national prevalence rate of child maltreatment (cf. [31]). Additionally, the NIS and NPM also include survey data from frontline professionals in other agencies that have frequent contact with children-for example, hospitals, day care centers, mental health agencies, and municipal police departments. In contrast to several population surveys that sometimes rely on small and nonrandom samples, professional surveys apply generally more rigorous methodological standards.

Examples of child maltreatment research using country-wide administrative data sets are particularly rare. In the US, a national database on children and families who come to the attention of state public child welfare agencies was permanently established in the early $1990 \mathrm{~s}$ $[32,33]$. Child protection agencies across the US systematically enter child maltreatment case data into online databases. US states then regularly submit these data to the National Child Abuse and Neglect Data System (NCANDS). Participation of individual US states in the NCANDS system is voluntary, but funding incentives 
for system development has motivated participation; the data system currently includes all 50 states [33]. Other nationally representative agency surveys and countrywide administrative data sets (e.g., for Australia, the Republic of Korea or the United Kingdom) are addressed in a separate overview [34].

Agency data and population surveys agree on the finding of higher rates for female than male victims of child sexual abuse and equal gender distribution for other types of maltreatment. In agency data, incidents of child sexual abuse are generally the least prevalent form of child maltreatment with percentages often around 3-9\% (e.g., $[27,30])$. The understudied phenomenon of child neglect, on the other hand, is by far the most prevalent form in agency data. Findings from agency data are also in agreement with surveys insofar as children are often not only subjected to one type of maltreatment, but multiple types- at the same time or by being victimized at different times in different contexts [35, 36].

\section{Trends}

The NCANDS provides the longest-running data set to analyze trends. Finkelhor et al. [37] have noted that rates of child sexual abuse $(-64 \%)$ and child physical maltreatment $(-55 \%)$ have both markedly dropped since the early 1990s. The promising trend in agency reported cases of child sexual abuse has been corroborated by a concurring decrease shown in several prevalence studies [38]. The evidence from population surveys shows trends similar to the agency data on declines for physical maltreatment [37]. However, hospital data show no decline in maltreatment-related injuries or fatalities [39]. For neglect, the most prevalent form of child maltreatment, there is some smaller decline in the period since 2006 in agency cases. There are similar data from New Zealand [40].

\section{Costs of child maltreatment}

Only a few studies have tried to estimate costs for a nation or region [41-45]. They concur in establishing child maltreatment as a serious public health issue that comes with large costs for a society. Indirect costs exceed the direct costs-loss of productivity has been identified as the most important element [44]. Definitional inconsistencies and methodological variations of underlying population surveys have led to a considerable variation of prevalence estimates and, consequently, estimates of child maltreatment costs. Habetha et al. [44] estimated 2008 per capita costs for Germany between 134.82 Euro and 363.58 Euro corresponding to $0.44 \%$ (lower bound) or $1.2 \%$ (upper bound) of Germany's GDP. The lower bound is close to the Australian estimate [45], while the upper bound is close to the Canadian estimate [41].
The relevant impact of child maltreatment on public health becomes even more important if intergenerational transmission is considered as an ongoing element (e.g., [46]): There is an increased risk for the offspring of child maltreatment victims to themselves experience similar adverse events (cf. [47]).

\section{Recommendations}

Child maltreatment comes with great costs for society and the need for more research on agency responses to child maltreatment has been stressed throughout this commentary. Progress in this area of research is however dependent on a collaborative effort between researchers, administrators, frontline staff and policy-makers. Building trust between these stakeholders is key for arriving at an effective knowledge-generating partnership. Trust is developed and nurtured through positive experiences and consistent contact [48]. Two major barriers have to be addressed to advance research on agency response to child maltreatment:

- The first-and probably the most important-step in this reciprocal and collaborative effort is a process of developing shared definitions between research and practice, e.g. through establishing a minimum data set that identifies a common set of variables for the tracking of child maltreatment [49]. This comprises measures of severity and chronicity of abuse to match the risk factors with future outcomes (e.g., [50]). Developing shared definitions is not just essential for research on agency response to child maltreatment, but also for future population surveys. This is especially important for neglect and psychological abuse as these types are harder to define and less conceptually clear than physical or sexual abuse (e.g., [5153]). Only shared definitions will allow for increased comparability of findings on prevalence and reported incidents to identify gaps in service provision.

- Second, in our experience, the major barrier and biggest threat to participation of agencies in surveys is work burden [48]. Frontline workers in child protection are continuously struggling to allocate scarce resources to the most urgent problems (e.g., [54]). Extra work for data collection will conflict with work time for clients or with the worker's free time. Workers need to perceive that the study is useful and important, and it is therefore essential to create a questionnaire that covers important issues while being brief, user-friendly and written in concise and clear language [48]. Innovative approaches to extracting data from files might also be developed [55]. 
Only more professional surveys will increase the relevant knowledge to identify gaps in service provision, to improve preventive efforts and increase opportunities for early intervention ([3], p. 3). If an evidence-base is lacking, initiatives to improve services for maltreated children are likely to not correspond with needs and rely on distorting factors such as media coverage or political sensibilities (e.g., [24]). These circumstances might be ones that have contributed to the 'neglect of neglect'. In sum, without knowledge about agency response to child maltreatment, we lack information about whether the costly investments in child welfare and protection are actually reaching the ones who need it the most (e.g., [56]). The UN Committee on the Rights of the Child [57] concludes that the right of the child to freedom from all forms of violence calls for "establishing a comprehensive and reliable national data collection system in order to ensure systematic monitoring and evaluation of systems (impact analyses), services, programmes and outcomes based on indicators aligned with universal standards, $[\ldots]$.

\section{Authors' contributions}

AJ has drafted and finalized the manuscript; DF and JF have critically revised and complemented the manuscript. All authors read and approved the final manuscript.

\section{Author details}

1 Department of Child and Adolescent Psychiatry/Psychotherapy, University of Ulm, Ulm, Germany. ${ }^{2}$ School of Social Work, Lucerne University of Applied Sciences and Arts, Lucerne, Switzerland. ${ }^{3}$ Crimes Against Children Research Center, University of New Hampshire, Durham, USA.

\section{Competing interests}

The authors declare that they have no competing interests.

Received: 17 February 2016 Accepted: 27 May 2016

Published online: 14 June 2016

\section{References}

1. Jud A, Rassenhofer M, Witt A, Münzer A, Fegert JM. Häufigkeitsangaben zum sexuellen Missbrauch. Internationale Einordnung, Bewertung der Kenntnislage in Deutschland, Beschreibung des Entwicklungsbedarfs. Berlin: Unabhängiger Beauftragter für Fragen des sexuellen Kindesmissbrauchs; 2016.

2. Fegert JM, Rassenhofer M, Witt A, Jud A. Häufigkeitsangaben sexuellen Missbrauchs und Inanspruchnahme von Hilfen. Trauma Gewalt. 2015;9:175-7

3. Leeb RT, Paulozzi L, Melanson C, Simon T, Arias I. Child maltreatment surveillance. Uniform definitions for public health and recommended data elements, version 1.0. Atlanta (GA). Centers for Disease Control and Prevention, National Center for Injury Prevention and Control; 2008.

4. Cicchetti D, Toth SL. Child maltreatment. Ann Rev Clin Psychol. 2005;1:409-38. doi:10.1146/annurev.clinpsy.1.102803.144029.

5. Corso PS, Edwards VJ, Fang XM, Mercy JA. Health-related quality of life among adults who experienced maltreatment during childhood. Am J Pub Health. 2008;98:1094-100.

6. Draper B, Pfaff JJ, Pirkis J, Snowdon J, Lautenschlager NT, Wilson I, Almeida OP. Long-term effects of childhood abuse on the quality of life and health of older people: results from the Depression and Early Prevention of Suicide in General Practice Project. J Am Geriatr Soc. 2008:56:262-71.
7. Fergusson DM, Boden JM, Horwood L. Exposure to childhood sexual and physical abuse and adjustment in early adulthood. Child Abuse Negl. 2008;32:607-19.

8. Gould F, Clarke J, Heim C, Harvey PD, Majer M, Nemeroff CB. The effects of child abuse and neglect on cognitive functioning in adulthood. J Psychiatr Res. 2012;46:500-6.

9. Shin SH, Miller DP, Teicher MH. Exposure to childhood neglect and physical abuse and developmental trajectories of heavy episodic drinking from early adolescence into young adulthood. Drug Alcohol Depend. 2013;127:31-8.

10. Jud A, Finkelhor D, Jones LM, Mikton C. Introduction. In: Jud A, Jones LM, Mikton C, editors. Toolkit on mapping legal, health and social services responses to child maltreatment. Geneva, Switzerland:WHO; 2015. p. 1-3.

11. Finkelhor D. The international epidemiology of child sexual abuse. Child Abuse Negl. 1994;18:409-17.

12. Barth J, Bermetz L, Heim E, Trelle S, Tonia T. The current prevalence of child sexual abuse worldwide: a systematic review and meta-analysis. Int J Public Health. 2013:58:469-83.

13. Pereda N, Guilera G, Forns M, Gomez-Benito J. The international epidemiology of child sexual abuse: a continuation of Finkelhor (1994). Child Abuse Negl. 2009;33:331-42.

14. Stoltenborgh M, van IJzendoorn MH, Euser EM, Bakermans-Kranenburg MJ. A global perspective on child sexual abuse: meta-analysis of prevalence around the world. Child Maltreat. 2011;16:79-101.

15. Stoltenborgh M, Bakermans-Kranenburg MJ, Alink LRA, van IJzendoorn $\mathrm{MH}$. The universality of childhood emotional abuse: a meta-analysis of worldwide prevalence. J Aggress Maltreat Trauma. 2012;21:870-90.

16. Stoltenborgh M, Bakermans-Kranenburg MJ, van IJzendoorn MH. The neglect of child neglect: a meta-analytic review of the prevalence of neglect. Soc Psychiatry Psychiatric Epidemiol. 2013;48:345-55.

17. Stoltenborgh M, Bakermans-Kranenburg MJ, van IJzendoorn MH, Alink LRA. Cultural-geographical differences in the occurrence of child physical abuse? A meta-analysis of global prevalence. Int J Psychol. 2013:48:81-94.

18. McSherry D. Understanding and addressing the "neglect of neglect". Why are we making a mole-hill out of a mountain? Child Abuse Negl. 2007;31:607-14.

19. Averdijk M, Müller-Johnson K, Eisner M. Sexual victimization of children and adolescents in Switzerland. Final report for the UBS Optimus Foundation. Zürich: UBS Optimus Foundation; 2012.

20. Radford L, Corral S, Bradley C, Fisher HL. The prevalence and impact of child maltreatment and other types of victimization in the UK. Findings from a population survey of caregivers, children and young people and young adults. Child Abuse Negl. 2013;37:801-13.

21. Radford L, Corral S, Bradley C, Fisher HL, Bassett C, Howat N, Collishaw S. Child abuse and neglect in the UK today. London: National Society for the Prevention of Cruelty to Children; 2011.

22. Dölitzsch C, Fegert JM, Künster AK, Kölch M, Schmeck K, Schmid M. Mehrfachdiagnosen bei Schweizer Heimjugendlichen [Multiple diagnoses in Swiss youths in residential care]. Kindh Entwickl. 2014;23:140-50.

23. Leenarts LE, Vermeiren RR, Ven PM, Lodewijks HP, Doreleijers TA, Lindauer RJ. Relationships between interpersonal trauma, symptoms of posttraumatic stress disorder, and other mental health problems in girls in compulsory residential care. J Traumatic Stress. 2013;26:526-9.

24. Jud A, Fluke J, Alink LR, Allan K, Fallon B, Kindler H, Lee BJ, Mansell J, van Puyenbroek $\mathrm{H}$. On the nature and scope of reported child maltreatment in high-income countries: opportunities for improving the evidence base. Paediatr Int Child Health. 2013;33:207-15.

25. Fallon B, Trocmé N, Fluke J, MacLaurin B, Tonmyr L, Yuan Y-Y. Methodological challenges in measuring child maltreatment. Child Abuse Negl. 2010;34:70-9

26. Sedlak AJ, Broadhurst DD. Third national incidence study of child abuse and neglect. Washington, DC: U.S. Department of Health and Human Services; 1996.

27. Sedlak AJ, Mettenburg J, Basena M, Petta I, McPherson K, Greene A, Li S. Fourth National Incidence Study of Child Abuse and Neglect (NIS-4). Report to Congress. Washington, DC: U.S. Department of Health and Human Services, Administration for Children and Families; 2010.

28. Public Health Agency of Canada (PHAC). Canadian incidence study of reported child abuse and neglect—2008. Major findings. Ottawa: PHAC; 2010. 
29. Trocmé N, Fallon B, MacLaurin B, Daciuk J, Felstiner C, Black T, Tonmyr L, Blackstock C, Barter K, Turcotte D, Cloutier R. Canadian incidence study of reported child abuse and neglect 2003. Ottawa: Minister of Public Works and Government Services Canada. Major Findings; 2005.

30. Euser S, Alink LR, Pannebakker F, Vogels T, Bakermans-Kranenburg MJ, Van $\mathrm{IMH}$. The prevalence of child maltreatment in the Netherlands across a 5-year period. Child Abuse Negl. 2013;37:841-51.

31. Fallon B, Trocmé N, MacLaurin B, Sinha V, Herbert A. Canadian incidence study of reported child abuse and neglect-2008: Process Evaluation Report. Toronto, ON: University of Toronto; 2010.

32. U.S. Department of Health \& Human Services. Child maltreatment 2012. Washington, DC: Author; 2013.

33. U.S. Department of Health and Human Services. Child maltreatment 2013. Washington, DC: Author; 2014.

34. Krüger $P$, Jud A. Overview of previous agency surveys and national administrative data sets. In: Jud A, Jones L, Mikton C, editors. Toolkit on mapping legal, health and social services responses to child maltreatment. Geneva, Switzerland: WHO; 2015. p. 4-9.

35. Finkelhor D. Childhood victimization. New York: Oxford University Press; 2008.

36. Finkelhor D, Ormrod R, Turner H, Holt M. Pathways to poly-victimization. Child Maltreat. 2009;14:316-29.

37. Finkelhor D, Saito K, Jones L. Updated trends in child maltreatment, 2013. Durham, NH: Crimes against Children Research Center; 2015.

38. Finkelhor D, Turner H, Ormrod R, Hamby SL. Trends in childhood violence and abuse exposure. Evidence from 2 national surveys. Arch Pediatr Adolesc Med. 2010;164:238-42.

39. Leventhal JM, Gaither JR. Incidence of serious injuries due to physical abuse in the United States. 1997 to 2009. Pediatrics. 2012;130:e847-52.

40. Ota R, Mansell J. Demand for child protection services. Wellington: Centre for Social Research and Evaluation, MSD; 2009.

41. Bowlus A, McKenna K, Day T, Wright D. The economic costs and consequences of child abuse in Canada. Ottawa: Law Commission of Canada; 2003

42. Fang X, Brown DS, Florence CS, Mercy JA. The economic burden of child maltreatment in the United States and implications for prevention. Child Abuse Negl. 2012;36:156-65.

43. Fang X, Fry DA, Brown DS, Mercy JA, Dunne MP, Butchart AR, Corso PS, Maynzyuk K, Dzhygyr Y, Chen Y, et al. The burden of child maltreatment in the East Asia and Pacific region. Child Abuse Negl. 2015;. doi:10.1016/j. chiabu.2015.02.012

44. Habetha S, Bleich S, Weidenhammer J, Fegert JM. A prevalence-based approach to societal costs occurring in consequence of child abuse and neglect. Child Adolesc Psychiatry Ment Health. 2012;6:35.
45. Taylor P, Moore P, Pezzullo L, Tucci J, Goddard C, De Bortoli L. The cost of child abuse in Australia. Melbourne: Australian Childhood Foundation and Child Abuse Prevention Research Australia; 2008.

46. Dixon L, Browne K, Hamilton-Giachritsis C. Risk factors of parents abused as children. a mediational analysis of the intergenerational continuity of child maltreatment (Part I). J Child Psychol Psychiatry. 2005;46:47-57.

47. Pears KC, Capaldi DM. Intergenerational transmission of abuse: a twogenerational prospective study of an at-risk sample. Child Abuse Negl. 2001;25:1439-61.

48. Jud A, AlBuhairan F, Ntinapogias A, Nikolaidis G. Obtaining agency participation. In: Jud A, Jones L, Mikton C, editors. Toolkit on mapping legal, health and social services responses to child maltreatment. Geneva, Switzerland: WHO; 2015. p. 55-62.

49. Ntinapogias A, Gray J, Durning P, Nikolaidis G. CAN-MDS policy and procedures manual. Athens: Institute of Child Health; 2015.

50. English DJ, Graham JC, Litrownik AJ, Everson M, Bangdiwala SI. Defining maltreatment chronicity. are there differences in child outcomes? Child Abuse Negl. 2005;29:575-95.

51. Coohey C. Making judgments about risk in substantiated cases of supervisory neglect. Child Abuse Negl. 2003;27:821-40.

52. Spertus IL, Yehuda R, Wong CM, Halligan S, Seremetis SV. Childhood emotional abuse and neglect as predictors of psychological and physical symptoms in women presenting to a primary care practice. Child Abuse Negl. 2003;27:1247-58.

53. Trocmé N, Fallon B, Maclaurin B, Chamberland C, Chabot M, Esposito T. Shifting definitions of emotional maltreatment: an analysis child welfare investigation laws and practices in Canada. Child Abuse Negl. 2011;35:831-40.

54. Tham P, Meagher G. Working in human services. How do experiences and working conditions in child welfare social work compare? Br J Soc Work. 2009;39:807-27.

55. Jud A, Knüsel R, Köhler J. The magnitude of legal, health and child protective services response to child maltreatment in Switzerland. Luzern: Hochschule Luzern; Université de Lausanne; 2014.

56. Wulczyn F, Daro D, Fluke J, Feldman S, Glodek C, Lifanda K. Adapting a systems approach to child protection. Key concepts and considerations. New York: United Nations Children's Fund (UNICEF); 2010.

57. UN Committee on the Rights of the Child. General comment No. 13. The right of the child to freedom from all forms of violence. New York: United Nations; 2011.

\section{Submit your next manuscript to BioMed Central and we will help you at every step:}

- We accept pre-submission inquiries

- Our selector tool helps you to find the most relevant journal

- We provide round the clock customer support

- Convenient online submission

- Thorough peer review

- Inclusion in PubMed and all major indexing services

- Maximum visibility for your research

Submit your manuscript at www.biomedcentral.com/submit 